\title{
Proposal of a Methodology for PSS Lifecycle- Oriented Design: Application in the Automotive Industry
}

\author{
Laura Cattaneo, Daniele Cerri, Sergio Terzi \\ Department of Economics, Management and Industrial \\ Engineering, \\ Politecnico di Milano \\ 20156 Milan, Italy \\ \{laura1.cattaneo, daniele.cerri, sergio.terzi\}@polimi.it;
}

\author{
Stefan Wellsandt \\ ICT applications for production \\ BIBA at the University of Bremen \\ 28359 Bremen, Germany \\ wel@biba.uni-bremen.de
}

\author{
Klaus-Dieter Thoben \\ Faculty of Production Engineering \\ University of Bremen \\ 28359 Bremen, Germany \\ tho@biba.uni-bremen.de
}

\begin{abstract}
The paper presents a methodology for the design of a Product-Service System (PSS). It has a focus on the integration of Internet of Thing technologies and the modelling of the PSS lifecycle. The methodology includes elaborated techniques, such as the Business Model Canvas and the Quality Function Deployment, as well as new tools like the construction of suitable matrices for put in evidence the IoT Capabilities. The lifecycle model is expressed with the Lifecycle Modeling Language (LML) and the modeling procedure is performed concurrently with each activity of the PSS design methodology. The methodology is tested in the automotive sector, because car companies realize growth opportunities in the service area.
\end{abstract}

Keywords- Product-Service System (PSS); Business Model Canvas (BMC); Quality function Deployment (QFD); Internet of Things (IoT); Lifecycle Modeling Language (LML); Automotive Industry

\section{INTRODUCTION}

Today, in an increasingly competitive world, companies need distinctive solutions, at least to keep their positions on the market. The ongoing globalization, the evolution of customer needs and expectations, the environmental aspects, the erosion of product margins and the intense competition have forced manufacturing companies to change their perspective toward new business models in order to secure additional sources of revenue and profits. This change is commonly termed as servitization [1]. This transformation has emerged essentially due to decreasing demands for products that become less attractive and from lower profits gained from selling pure products [2]. Thus, new market potentials and higher profit margins become possible as well as higher customer loyalty and customer feedback are feasible [3].
Within the servitization, Product-Service System (PSS) represents an essential topic. A PSS is an integrated product and service offering that delivers value in use to the customer. There are several potential benefits PSS. Firstly, there is an increase of revenues, because services tend to have higher profit margins and can provide a stable and countercyclical source of revenues. Secondly, they are means to differentiate offers in mass-markets, that are typically characterized by commodities and technologies. Lastly, services bring a decrease of variability and volatility of cash flow throughout the life of a product resulting in a higher shareholder value [4].

The business model of PSS is promoted also by the Internet of Things (IoT) technologies, which enable the introduction of new services related to the connectivity and the using of environmental data. Connected products offer expanding opportunities for new functionality, greater reliability, higher product utilization and capabilities that cut across and transcend traditional product boundaries. Terms like CyberPhysical Systems, IoT and Virtual Reality have become ordinary in industries as everyday issues. IoT products raise a new set of strategic choices related to how value is created and captured, how the prodigious amount of data they generate is utilized and managed and what role companies should play as industry boundaries are expanded [5].

The goal of this paper is to offer a design methodology for PSS, which takes the lifecycle perspective into account. This methodology serves as a basis for the identification of relevant data, information and knowledge, meant to be managed by combined lifecycle management. Lifecycle models describe, in a simplified way, important steps a product or service has to pass while it exists. From an engineering perspective, lifecycle models provide system boundaries for management tasks. The information needed to create the methodology comes from elaborated and new methodologies, with a particular attention 
to the integration of the IoT technologies. The target audience of this paper is researchers and practitioners in the PSS domain.

The methodology is tested in the automotive sector. Many automotive companies are moved from traditional productcentered business models to service-based differentiation, where focus of business strategy moves from selling physical products to combining products and services, to solve customer problems and create value. Many automotive companies realized enormous growth opportunities in the service area and various categories of services exist in the automotive market: maintenance and repair, insurance, finance, lease, experience centers, test drives, sales consulting and so forth [6]. Nonetheless, the authors are involved in a European Project, 'Manutelligence' [7], together with an important automotive company partner, so that the PSS methodology is actually tested on this specific use case.

The paper is organized as follows: in Section II the research statement is outlined, explaining the rationale of the research and introducing the proposed PSS design methodology. In Section III the methodology is explained in details and in Section IV the methodology is tested on a test case from the automotive industry. Section $\mathrm{V}$ outlines the research conclusion, putting in evidence some open issues and some critical aspects of the proposed methodology.

\section{THEORETICAL BACKGROUND}

Product-Service System (PSS) is a complex matter, because it is composed by several parts that need to be handled: a product and one or more related services, a network of players and a supporting infrastructure [8]. The different product aspects, such as the concept and design phases and the lifecycle, have been analyzed deeper by many authors [9]. From these studies emerged methodologies, such as System Engineering and Product Lifecycle Management's (PLM) models, that can be used to properly manage the product life cycle. The service topic is more recent and methodologies, such as Service Engineering, are first attempts for structuring the service design [3].

According to Wellsandt et al., a lifecycle model describes the lifecycle of a product in a simplified way [10]. It contains elements that represent processes, stakeholders and flows of material, energy, waste and information. The elements are geometrically arranged, e.g. linear or circular shaped. A lifecycle model may integrate one or more lifecycles at once for instance, the lifecycle of a manufacturing machine and the created product. The complexity of a model depends on its purpose. The models investigated in [10], for instance, are mainly used to give an overview about different concepts discussed in the papers the models belong to. A lifecycle model with a much higher granularity is provided, for instance, by Anke, Wellsandt and Thoben [11]. The authors describe a lifecycle model that could be used in the course of a PSS design for a material replenishment service for 3D-printers (it is a theoretical case). Its purpose is to support stakeholders in understanding the effects of the interacting components of a PSS.

From the literature emerges that there exist some gaps, since few models describe in details how to identify and manage the key data to evaluate PSS performance. Moreover, few models explain clear and step-by-step methodologies to support companies in the utilization of IoT technologies.

\section{APPROACH}

The main goals of the methodology are to structure the concept and design phase of the PSS and to identify the IoT technologies needed to catch and elaborate the useful data for the customer needs satisfaction. One part of this methodology foresees the definition of a model of the PSS that takes the lifecycle perspective into account. The information needed to create the model comes from elaborated and new methodologies, with a particular attention to the integration of the IoT technologies. The lifecycle model is expressed with the Lifecycle Modelling Language (LML) [12]. The LML is a derivative of the Systems Modelling Language (SysML) of the Open Group. Both are used to describe technical systems with formalized entities and relations. The specification of LML contains a formal description of concepts. These concepts and their relations are stored as Ontology - i.e. a semantic network of concepts. The relations between concepts have different meanings, e.g. "decomposed by" or "created by". Wellsandt, Anke and Thoben used LML in the context of PSSs conceptual design [13].

The design methodology contains multiple activities to gather information and use them to build a lifecycle model of a PSS. In order to demonstrate the methodology, three example activities will be covered in this paper. Within these three activities, we include elaborated techniques, such as the Business Model Canvas (BMC) and the Quality Function Deployment (QFD), as well as new tools like the matrices used for defining the IoT Capabilities. Fig. 1 illustrates the three selected activities. Besides these three tasks, there are other many important tasks to be considered, especially concerns the design of the actual solution components. The main three activities should be completed and integrated with other important information, as well as the addition of hard- and software functionalities and business processes.
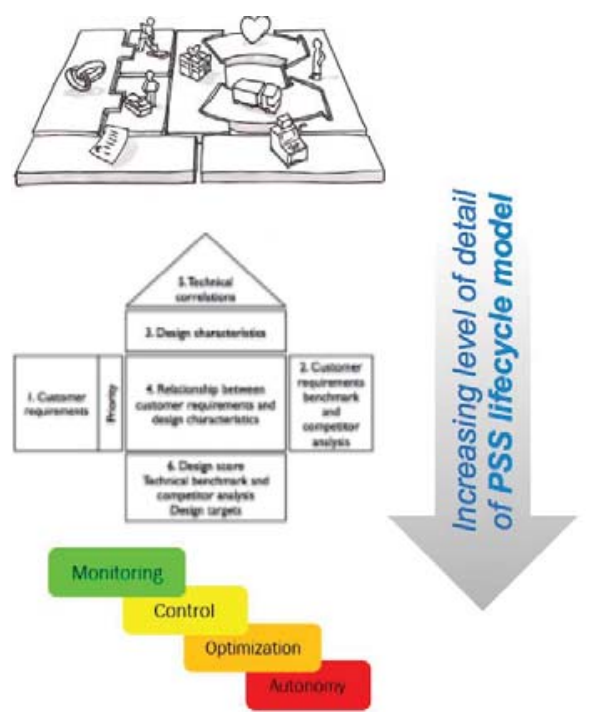

Fig. 1. Design methodology. 


\section{A. Activity 1: Business Model Design}

The goal of this activity is the definition of the PSS's Business Model. The Business Model will be designed through the use of the Business Model Canvas and the Value Proposition Canvas.

The Business Model Canvas is a method that assists company in achieving the better business plan solution and it is described in the Business Model Generation book [14]. The Business Model Canvas enables the creation of new Business Model or improves the pre-existent ones. Canvas elements are: Key partners, Key activities, Key resources, Customer segments, Cost structure and Revenue stream. This information is necessary to construct the lifecycle model.

Supporting the Business Model Canvas, the Value Proposition Canvas [15] could be eventually developed, helping to create value for the customer. The Business Model Canvas and the Value Proposition Canvas are chosen in order to have a customer centric point of view, since the focus in the whole methodology should be the satisfaction of the customers' needs. The output of the Activity 1 is a complete Business Model at strategic level, which means having a complete view of who will be the actors, which will be the product, the activities and the services provided, the costs structure and the structure of the revenue streams.

\section{B. Activity 2: Requirements Definitions}

The goal of Activity 2 is defining the requirements derived from the Business Model Design step. In order to achieve this result we decide to implement the Quality Function Deployment (QFD) method [16]. QFD is a structured approach to define customer needs and translating them into specific product requirements. The basic QFD methodology involves four phases that occur over the course of the product development process. During each phase one or more matrices are prepared to help communicate critical issues, process planning and design information. Among these four phases, we use the first one, the Product Planning/Performance Requirements phase. This phase is also famous as House Of Quality (HoQ). It documents customer needs, which are then summarized in a product/planning matrix.

The innovation of Activity 2 is the application of the HoQ to find the PSS requirements, so that some parts could be different from the classical HoQ, which typically involves only product specifications. The HoQ presented in this work has some peculiarity, in order to be suitable for the Product-Service System characteristics. The parts composing the innovative HoQ are the following:

- Voice of the Customer. It documents a structured list of a product's customers' requirements described in their own words. The list of requirements gathered in such an exercise must be structured before its entry into the HoQ

- Voice of the Company. It is necessary to highlight also the company's needs, for example data collectors, in order to develop suitable services. In some particular cases, the company could apply weights to the customers' and to the company's needs, according to its goals.

- In our application, the Design Inputs part is divided between product technical requirements and service technical requirements. The new configuration permits to have a whole view on the Product-Service System.

- Product-Service Planning Matrix: this section forms the main body of the HoQ matrix and can be very time consuming to complete. Its purpose is to translate the requirements as expressed by the customer into technical characteristics of the product. Its structure is that of a standard matrix with cells that relate to combinations of individual customer needs and technical requirements. It is the task of the QFD team to identify where these interrelationships are significant.

The inputs for the blocks of the HoQ come from the previous activity, particularly from the Value Proposition Building Block and the Key Resources Building Block, where the customers' needs are defined at the strategic level. With the help of the HoQ, this information gives in output the technical requirements and the engineering target values of the ProductService System.

\section{Activity 3: IoT Capabilities Definition}

This activity represents the core part of the proposed methodology, since during this activity it is possible to define the bases for the Product-Service design phase. Three different processes could be simultaneously developed: the Product Design, the Service Design and the Product-Service Design. The outputs coming from these processes will be the Bill of Material of the product, the definition of the connected services and the identification of data, information and knowledge that should be managed and analyzed during the Product-Service lifecycle.

Smart products have three main components: physical components, smart components and connectivity components. Smart components are directly connected with services related to the physical parts, while connectivity allows exchange information between the product and its operating environment and enables some services to exist outside the physical product itself [5]. Connect products require the design of a new technology infrastructure made up of multiple layers, therefore to properly design the PSS is necessary to identify sensors, software, data storage, users interface as well as ports, protocols and kind of connections. In the meanwhile it is necessary to satisfy the stakeholders requirements derived from Activity 2.

Usually the Product Design and the Service Design processes are separately developed, within different specialized team, which propose solutions that often are not really integrated. The innovation of the methodology aims to improve the integration between Product and Service Design in order to give to customers the best PSS solution. The methodology includes the classical System Engineering (Product Design) and Service Engineering models (Service Design) [3, 17], 
which are led and integrated by an interdisciplinary group composed by product and service experts. Starting from the requirements defined in the previous phases, the team will implement the Product-Service Design with the primary aim of defining the IoT capabilities that should be integrate in the product lifecycle in order to properly design the connected services. Following the classification made in [5], the capabilities of smart product can be grouped into four areas: monitoring, control, optimization and autonomy.

- Monitoring: sensors and external data sources enable the monitoring of the product's conditions, the external environment and the product's usage. Monitoring also enables alerts and notifications of changes.

- Control: software embedded in the product enables control of product functions and personalization of the customer experience.

- Optimization: monitoring and control capabilities enable algorithms that optimize product operations in order to enhance the performances and allow predictive diagnostics, services and repair.

- Autonomy: combine monitoring, control and optimization allows autonomous product operations, self-coordination and self-diagnosis.

Exploiting the Bill of Material, which is developed in the product design phase, we design a matrix structure for each product's systems and subsystems. The number of systems and subsystems automatically defines a number of levels and for each level we design a specific matrix (e.g. for a smart car, level 0: vehicle, level 1: Power Unit, Gear Box, Car Body, etc.). For each level, the product's parts are reported as input for the designed matrix. The second axis includes data destination or the stakeholders who need a specific kind of information (real customer, companies' teams-work and so on). Each matrix entry indicates if a specific part enables or not a specific service, who is the recipient of the information and, in the meanwhile, it indicates which IoT capability is activated (Monitoring, Control, Optimization or Autonomy), as is reported in Fig. 2. A white box means that no IoT capabilities are defined for that entry. The IoT capability is selected in order to satisfy the product and service requirements. This classification is an important initial stage, since a specific IoT capability defines the correspondent technology to select, such as sensors or data storage systems, and clarify the kind of connection that must be developed.

\begin{tabular}{|c|c|c|c|c|c|c|}
\hline & & \multicolumn{5}{|c|}{ \# Level } \\
\hline & & Part 1 & Part 2 & Part 3 & Part 4 & Parts \\
\hline \multirow{4}{*}{ 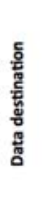 } & Software & Control & & Monitoring & & \\
\hline & Designers & & & & & \\
\hline & Maintenance & & & & Monitoring & \\
\hline & App & & Monitoring & & Optimization & \\
\hline
\end{tabular}

Fig. 2. Matrix example.

\section{PSS Lifecycle Modelling}

The information created during the BMC, QFD and IoT assessments are used to model the PSS lifecycle with LML. The modeling procedure is performed concurrently with each step of the design methodology. Further, information collected outside the three steps may be integrated into the model any time.

\section{1) Using BMC information in the lifecycle model}

In this paper, the starting point of the lifecycle model is the information created during the BMC task. This information may include more than the illustration of the resulting canvas though, the authors of this paper lack examples at this point of the study. Table I contains a proposal for the relations between canvas elements and entities defined in the LML specification.

TABLE I. RELATIONS BETWEEN BUSINESS MODEL CANVAS INFORMATION AND LIFECYCLE MODELLING LANGUAGE ENTITIES

\begin{tabular}{|l|l|l|}
\hline BMC information & & LML entities \\
\hline Key partners & $\Rightarrow$ & Assets \\
\hline Key activities & $\Rightarrow>$ & Activity \\
\hline Key resources & $\Rightarrow>$ & Resource, asset \\
\hline Customer segments & $\Rightarrow>$ & Assets \\
\hline Cost structure & $\Rightarrow>$ & Cost \\
\hline Revenue streams & $\Rightarrow>$ & Input/Output (I/O) \\
\hline
\end{tabular}

The authors of this paper experienced the remaining canvas elements, i.e. value propositions, customer relationships, and channels, as difficult. This is mainly because the elements have no clear match with existing LML entities. The channels' element, for instance, might be realized with Conduit and I/O entities or with a mix of I/O, Asset and Activity entities.

At the end of the BMC the lifecycle model should contain key stakeholders (partners and customers), activities, resources and cost. Details about technical and organizational measures to realize the PSS are missing yet.

\section{2) Using QFD information in the lifecycle model}

The purpose of this part of the modeling procedure is to derive stakeholder requirements and technical specifications of the PSS from the QFD (i.e. HoQ). The relation between QFD information and LML entities is outlined in the following list:

- Voice of the customer. The perspective of the customer (and other stakeholders) is expressed with the Statement entity. In this context, the statement is a description in the customer's language.

- Voice of the company. The statements of customers are translated into specifications. These are expressed in the company's language (e.g. technical wording). Specifications can be represented in LML by using the Requirement entity.

The defined specifications (which may still evolve over time) feed into the design of the required solution components of the PSS. While they become clearer in the course of engineering design, service engineering, software development and other processes, the lifecycle model becomes more detailed as well. This concerns, for instance, the addition of hard- and software functionalities, as well as business processes, such as 
procurement, maintenance and recycling. A list of potentially relevant business processes is provided in [16].

The solution-related elements of the model are connected to the formerly defined requirements, while the requirements are connected to customer (or other stakeholders') statements. In the case that a stakeholder doesn't know why a PSS component was modeled, these relations become helpful.

\section{3) Using IoT information in the lifecycle model}

The purpose of this part of model building is to describe functionalities related to monitoring, control, optimization and autonomy of the PSS's hardware (the IoT components). For this purpose, Action and Asset entities may be added, such as data generation through measurement, and data processing that turns data into useful information. The resulting information is conveyed via communication channels - these can be described through Conduit and I/O entities.

\section{APPLICATION}

Many automotive companies, especially in the luxury car segment, are expanding their service business and service scope: traditional after-sales services, such as maintenance and repair, are supplemented with finance and insurance services. Moreover, automotive manufactures and retailers now actively promote many customer experience-enhancing services, such as museum visits, plant tours and brand magazines [18].

The methodology described in the previous chapter is tested in the automotive sector, in order to verify if it is suitable for a real Product-Service System. The methodology is applied in all the three activities presented above (Business Model definition, Requirements definition and IoT Capabilities definition). In order to have an understandable example, it is focused on the IoT Capabilities Design and some aspects of the classical PSS development are deliberately skipped. The methodology aims to structure the concept and design phase of the PSS in the automotive sector, in order to create suitable platform to collect and manage data from field. These data are gathered through IoT technologies.

\section{A. Activity 1: Businees Model Design}

Activity 1 starts with the definition of the Business Model of the PSS, in order to define actors, activities, goals, costs and revenues and to structure them. Business Model Canvas and the Value Proposition Canvas are constructed. The analysis starts with the definition of the customers' needs. Part of the information directly comes from the company, while other parts are collected from similar cases found in literature. Fig. 3 reports the Business Model Canvas developed for our case.
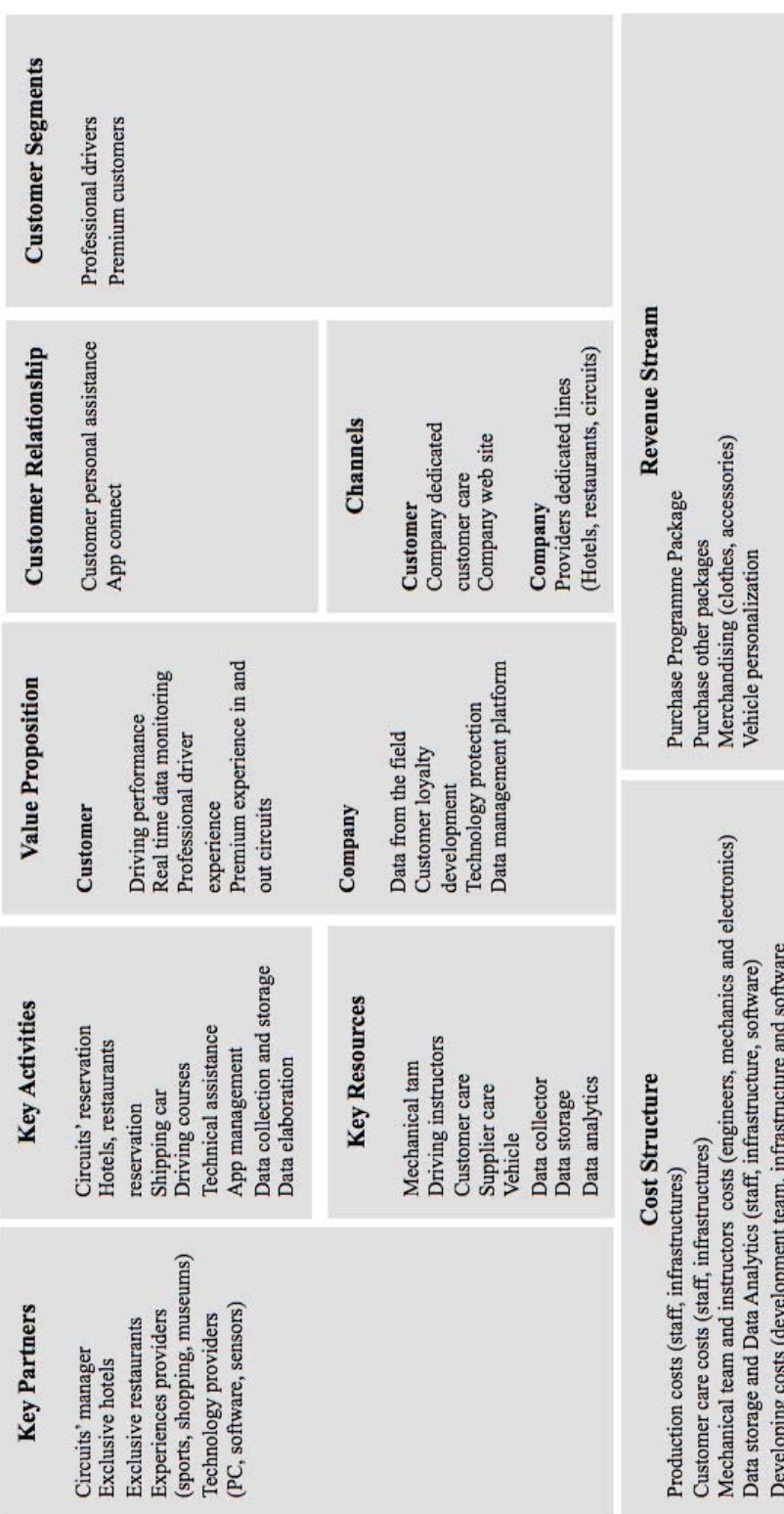

Fig. 3. Test case Business Model Canvas (BMC).

\section{B. Activity 2: Requirements Definitions}

During this phase, the inputs coming from the BMC and the Value Proposition Canvas are translated into technical requirements. These requirements will then be use to design product and services in Activity 3.

The HoQ presented in this work has some peculiarity, in order to be suitable for the Product-Service System characteristics. In particular, the HoQ developed for our test is reported in Fig. 4. It presents some simplifications, such as

- The "Competitive Assessment" part is not developed because there is not a similar comparative real case in the automotive market. 
- We have selected different scores in the "Relationship Matrix" part to indicate the magnitude of the interrelationship between the "Voice of the Customer", the "Voice of the Company" and the "Technical Requirements": strong inter-relationship (mark: 9), medium inter-relationship (mark: 6), weak interrelationship (mark: 3). Therefore, the entries of the table are the result of the product between the relationship scores and the Importance Weighting scores.

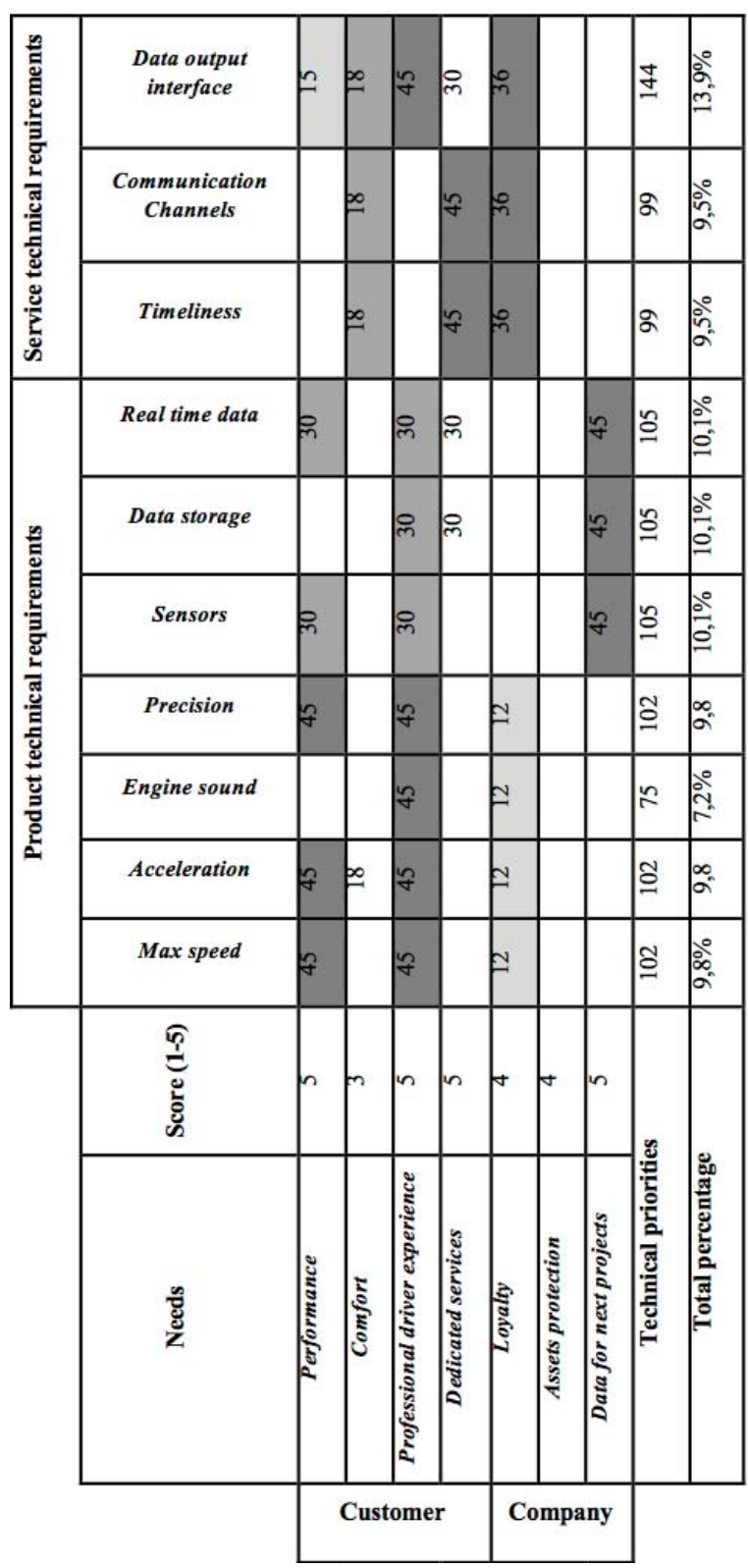

Fig. 4. Test case House of Quality (HoQ).

\section{Activity 3: IoT Capabilities Definition}

The goal of this last activity is to define the IoT capabilities at each level of the BoM, in order to satisfy the specific requirements. It receives as inputs the requirements defined during Activity 2. In this specific application a simplified BoM and the connected capabilities matrices are introduced. The definition of the System Engineering and Service Engineering processes will be skipped, since they are not relevant for this example.

The BoM is defined through a model car BoM analysis. It is composed by three levels (the 0 product level is not considered), which define the whole structure of the vehicle. The BoM's level of detail could change from case to case and from company's preferences and needs (number of systems, subsystems and components considered). After the BoM definition, suitable matrices are used to identify the IoT Capabilities at each BoM level. Fig. 5 summarizes examples from the application case.

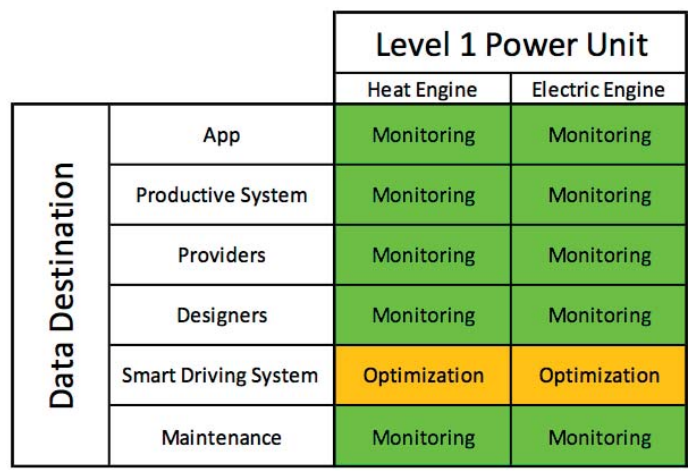

\begin{tabular}{|c|c|c|c|c|c|c|}
\hline & \multicolumn{5}{|c|}{ Level 2 Heat Engine } \\
\hline & & Belt & Turbine & Monoblock & Exhaust System & Cylinder \\
\hline \multirow{6}{*}{ 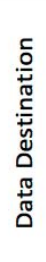 } & App & & & & Monitoring & \\
\hline & Productive System & Monitoring & Monitoring & & & \\
\hline & Providers & Monitoring & Monitoring & & & \\
\hline & Designers & Monitoring & Monitoring & & Monitoring & Monitoring \\
\hline & Smart Driving System & Monitoring & Optimization & & Optimization & Optimization \\
\hline & Maintenance & Monitoring & Monitoring & & Monitoring & Monitoring \\
\hline
\end{tabular}

\begin{tabular}{|c|c|c|c|c|}
\hline & & \multicolumn{3}{|c|}{ Level 2 Electric Engine } \\
\hline & & Solenoid & Energy Recovery Sys. & Battery Back \\
\hline \multirow{6}{*}{ 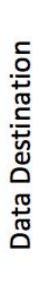 } & App & & Monitoring & Monitoring \\
\hline & Productive System & Monitoring & Monitoring & \\
\hline & Providers & Monitoring & Monitoring & \\
\hline & Designers & Monitoring & Monitoring & \\
\hline & Smart Driving System & Monitoring & Optimization & \\
\hline & Maintenance & Monitoring & Monitoring & Monitoring \\
\hline
\end{tabular}

Fig. 5. Example of matrices constructed for the use case IoT capabilities definition. 
For each entry we define if a particular IoT capability is present or not. Referring to [5], IoT capabilities are classified as Monitoring, Control, Optimization and Autonomy. In Fig. 4, green colors indicate the Monitoring activity while orange colors refer to Optimization activity. A white box means that no IoT Capabilities are defined for that entry.

Data and information will be collected in a suitable platform [7]. Data, since they are acquired from different hardware, are then synchronized in order to have coherent dataset. Regarding the automotive case, most of the data are directly used to initialize numerical models to simulate particular car conditions. In other cases, data are used to compare numerical data and experimental data. Thanks to this analysis, it should be possible to give feedback to the design process through comparison between virtual model and experimental tests, leveraging on the possibility to virtually simulate the mechanism behaviour in different conditions.

\section{DISCUSSION AND CONCLUSION}

This paper presents a methodology for the design of PSSs, with a particular attention to the integration of IoT technologies and the Product-Service lifecycle modeling. The information needed to create the model comes from elaborated techniques used in product and service engineering, such as the BMC and the QFD. In order to demonstrate the methodology, three example activities have been covered in this paper. One activity is devoted to the integration of IoT technologies. This part of the proposed methodology is new. The matrices constructed at this activity provide a structured assessment of IoT functions.

The lifecycle modeling is expressed with LML, which is a derivative of SysML of the Open Group. The information created during the BMC, QFD and the IoT evaluation is used to model the PSS lifecycle with LML. The modeling procedure is performed concurrently with the design methodology. Further, information collected outside the three example activities may be integrated into the model any time.

This methodology should be considered as an initial stage of the development of a more comprehensive method. The PSS design methodology, presented in this work, leaves out many important tasks. This especially concerns the design of the actual solution components. The three example activities should be completed and integrated with other information, as well as the addition of hard- and software functionalities and business processes, such as procurement, maintenance and recycling. Further, it is necessary to test the methodology in other sectors, besides the automotive one, to better understand which kind of data are necessary to satisfy customer requirements and to develop suitable IoT technologies.

\section{ACKNOWLEDGMENT}

This work was funded by the European Commission through Manutelligence Project (GA_636951). The authors wish to acknowledge their gratitude to all the partners for their contributions during the development of concepts presented in this paper.

\section{REFERENCES}

[1] A. D. Neely, "Exploring the Financial Consequences of the Servitization of Manufacturing", Operations Management Research, vol 2, no 1, pp 103-118, 2009.

[2] G. Vasantha, R. Roy, A, Lelah and D. Brissaud, "A review of productservice systems design methodologies,” J. Eng. Des., vol. 23, no. 9, pp. 635-659, 2012.

[3] J. C. Aurich, C. Mannweiler, and E. Schweitzer, "How to design and offer services successfully,” CIRP J. Manuf. Sci. Technol., vol. 2, no. 3, pp. 136-143, 2010.

[4] S. Cavalieri, G. Pezzotta, "Product-Service Systems Engineering: State of the art and research challenges", Computers in Industry, vol 63, no. 4, pp 278-288, 2012.

[5] M. E. Porter and J. E. Heppelmann, "How Smart, Connected Products are trasforming competition.", Harvard Business Review, November 2014

[6] O. Godlevskaja, J. van Iwaarden, T. van der Wiele, "Moving from product-based to service- based business strategies: Services categorisation schemes for the automotive industry", International Journal of Quality \& Reliability Management, Vol. 28 Issue: 1,pp. 6294, 2011.

[7] Manutelligence consortium, "Manutelligence project," 2015. [Online]. Available: http://www.manutelligence.eu/. [Accessed: 21-Jan-2016].

[8] M. J. Goedkoop, C. J. G. van Halen, H. R. M. te Riele and P.J.M. Rommens, "Product Service-Systems, ecological and economic basics." Report for Dutch Ministries of Environment (VROM) and Economic Affairs (EZ), 1999.

[9] K. T. Ulrich and S. D. Eppinger, "Product Design and Development: Fifth Edition", 2007.

[10] S. Wellsandt, E. Nabati, T. Wuest, K. A. Hribernik, and K. D. Thoben, "A survey of product lifecycle models: towards complex products and service offers," International Journal of Product Lifecycle Management, vol. 9 , no. 4, p. 353, 2016.

[11] J. Anke, S. Wellsandt, K.-D Thoben, "Modelling Life Cycles of Smart Services. Enterprise Modelling and Information Systems Architectures". Unpublished.

[12] Lifecyclemodeling.org, "Lifecycle Modeling Language," A simple ontology with common graphical notations that makes design make sense, 2015. [Online]. Available: http://www.lifecyclemodeling.org/. [Accessed: 12-Jun-2015].

[13] S. Wellsandt, J. Anke, and K.-D. Thoben, "Modellierung der Lebenszyklen von Smart Services für vernetzte Produkte am Beispiel der Bereitstellung von Verbrauchsmaterialien," presented at the Dienstleistungsmodellierung 2016, Karlsruhe, 2016.

[14] A. Osterwalder and Y. Pigneur. "Business model generation: a handbook for visionaries, game changers, and challengers”. John Wiley \& Sons, 2010..

[15] A. Osterwalder, Y. Pigneur, G. Bernarda, A. Smith and T. Papadakos, "Value Proposition Design: How to Create Products and Services Customers Want", John Wiley \& Sons, 2014.

[16] Y. Akao, "Quality Function Deployment”, 2004.

[17] V. D. Bhise, "Design complex products with systems engineering processes and techniques", CRC Press, Taylor \& Francis Group, 2014.

[18] B. J. Pine, J. H. Gilmore, "Welcome to the experience economy", Harvard Business Review, pp 97-105, July-August 1998. 